\title{
BILATERAL FACIAL PALSY: POST VIVAX MALARIA SCENARIO
}

\author{
Vinayak Sawardekar1, Rohit Patil2, Akash Badgujar 3 , Shriram Nawade, ${ }^{4}$ ijay Krishna Joglekar 5
}

${ }^{1}$ Assistant Professor, Department of Medicine, Grant Medical College \& Sir J. J. Group of Hospitals, Mumbai.

21 st Year Junior Resident, Department of Medicine, Grant Medical College \& Sir J. J. Group of hospitals, Mumbai.

33rd Year Junior Resident, Department of Medicine, Grant Medical College \& Sir J. J. Group of Hospitals, Mumbai.

41st Year Junior Resident, Department of Medicine, Grant Medical College \& Sir J. J. Group of Hospitals, Mumbai.

5Professor and HOD, Department of Medicine, Grant Medical College \& Sir J. J. Group of Hospitals, Mumbai.

\section{ABSTRACT}

Malaria can cause severe complications, sometimes affecting central nervous system. Cranial nerve palsies are rare after malaria. Plasmodium vivax malaria, often thought to be a benign disease can sometime lead to severe complications. We report a case of lower motor neuron palsy after plasmodium vivax malaria.

\section{KEYWORDS}

Facial Palsy, Vivax Malaria.

HOW TO CITE THIS ARTICLE: Sawardekar V, Patil R, Badgujar A, et al. Bilateral facial palsy: post vivax malaria scenario. J. Evolution Med. Dent. Sci. 2016;5(62):4400-4401, DOI: 10.14260/jemds/2016/1005

\section{INTRODUCTION}

Malaria is a common health problem in tropical countries like India. Of the four plasmodium species causing malaria in humans, P. vivax is the most widespread. P. vivax malaria in India is more prevalent than plasmodium falciparum. ${ }^{1}$ In India P. vivax and P. falciparum accounts for about $60-65 \%$ and $35 \%$ cases respectively. ${ }^{2} \mathrm{P}$. vivax is often thought to be benign infection; however, it may sometime result in severe complications affecting different organs. ${ }^{3}$

Commonly reported severe complications of P. vivax malaria include haematological problems, such as anaemia and thrombocytopenia, liver or kidney dysfunction, lung related complications, hypoglycaemia, shock and cerebral malaria.2,3 We report here an unusual case of bilateral lower motor neuron palsy after P. vivax malaria.

\section{CASE PRESENTATION}

A 25-year-old male patient, clerk by profession presented with chief complaints of drooling of saliva from both angles of mouth and inability to close eyes since last 5-6 days. There was no history of weakness in any limb, no history of dry cough, breathlessness on exertion, history of trauma, convulsion, difficulty in swallowing, nasal regurgitation, long distance travel, exposure to cold environment, increased thirst, increased urine output, painful skin lesions in ears, high risk sexual behaviour or hypo-aesthetic skin patches. The patient had no history of diabetes mellitus, stroke or hypertension.

He had history of Plasmodium vivax malarial fever 15 days before admission. The patient had received anti-malarial treatment; however, he had not taken radical treatment. There was no significant relevant family history. The patient had no bowel or bladder complaints. Sleep was adequate with normal appetite.

Financial or Other, Competing Interest: None.

Submission 18-05-2016, Peer Review 21-07-2016,

Acceptance 27-07-2016, Published 04-08-2016.

Corresponding Author:

Dr. Vinayak Sawardekar,

A5, Rameshwar Soc.,

Near Thane Municipal Corporation

Panchpakhadi,

Thane (w)- 400602.

E-mail: vinayaks1812@gmail.com

DOI: $10.14260 /$ jemds/2016/1005
On examination, general condition was fair. The patient was afebrile with regular pulse rate of 78 per minute. Blood pressure and respiratory rate was $110 / 70 \mathrm{mmHg} 16 / \mathrm{min}$ respectively. There was no pallor, icterus, clubbing, cyanosis, pedal oedema, hypoaesthetic skin lesions or thickened nerves. Jugular venous pressure was normal.

The patient was conscious, co-operative and oriented in time, place and person. All higher functions were normal except dysarthric speech.

Cranial nerve examination was normal except bilateral lower motor neuron type facial nerve palsy. Bilateral Bell's phenomenon was positive with drooling of saliva from both angles of mouth without wrinkling on forehead, naso-labial folds on both sides and inability to smile.

Motor system, sensory system examination, coordination, gait and cerebellar examination were normal. There were no involuntary movements. Cardiovascular system, respiratory system and per abdomen examinations were normal. The investigational reports are given in Table 1.

\begin{tabular}{|c|c|}
\hline Investigation & Result \\
\hline Haemoglobin & $13.7 \mathrm{gm} / \mathrm{dL}$ \\
\hline Platelet count & $225000 / \mathrm{cmm}$ \\
\hline White Blood Cells (WBC) & $6790 / \mathrm{cmm}$ \\
\hline Creatinine & $1.1 \mathrm{mg} / \mathrm{dl}$ \\
\hline Urea & $22 \mathrm{mg} / \mathrm{dl}$ \\
\hline Sodium & $137 \mathrm{mEq}$ \\
\hline Potassium & $4.2 \mathrm{mEq}$ \\
\hline Total Bilirubin & $0.7 \mathrm{mg} / \mathrm{dL}$ \\
\hline SGOT & $20 \mathrm{IU} / \mathrm{mL}$ \\
\hline SGPT & $10 \mathrm{IU} / \mathrm{mL}$ \\
\hline $\begin{array}{c}\text { Erythrocyte Sedimentation } \\
\text { Rate }\end{array}$ & $10 \mathrm{~mm}$ at end of one \\
Table 1: Investigations \\
\hline \multicolumn{2}{|c}{} \\
\hline
\end{tabular}

Chest X-ray and ECG were within normal limit. Malarial antigen, NS1 antigen, IgM Dengue, IgM Lepto, IgM, IgG Herpes simplex virus, IgM, IgG Lyme's disease, IgM, IgG Epstein-Barr virus were negative. Glucose-6-phosphate dehydrogenase (G6PD) enzyme level was also within normal range. Routine microscopy of Cerebrospinal Fluid (CSF) revealed protein 25 $\mathrm{mg} \%$ and sugar $60 \mathrm{mg} \%$ with no presence of WBC or red blood cells. Gram staining of CSF was negative. High resolution computed tomography of thorax, Magnetic Resonance Imaging 
(MRI) of brain did not reveal abnormality. There was no hilar and mediastinal lymphadenopathy. Referral to Ear Nose Throat (ENT) specialist and dermatologist did not show any significant abnormalities. Neurology referral revealed an impression of post plasmodium vivax malarial fever bilateral lower motor neuron facial palsy.

The patient was advised acyclovir $400 \mathrm{mg}$ three times a day for 10 days, prednisolone $60 \mathrm{mg}$ once a day early morning with a glass of milk to be tapered over a period of three weeks. Moreover, the patient was given radical treatment for vivax malaria with primaquine $30 \mathrm{mg}$ once a day for 14 days after confirming normal G6PD levels. Physiotherapy was given for strengthening of facial muscles in the form of facial massage and facial nerve stimulation. The patient started showing improvement in weakness after 2 months, but still has some residual weakness after 3 years.

\section{DISCUSSION}

Malaria can sometimes cause central nervous system related complications such as cerebral malaria, which may lead to sequelae such as Guillain-Barre Syndrome (GBS), cerebellar ataxia, extra-pyramidal symptoms, trismus, peripheral neuropathy, isolated 6th nerve palsy or rarely other cranial nerve palsies. ${ }^{4}$ The neurological spectrum of patients infected with P. vivax is limited due to small number of reported cases. Central nervous system related complications such as Acute Demyelinating Encephalomyelitis (ADEM).5,6 due to p. vivax have been reported. Bilateral sixth cranial nerve palsy due to Plasmodium falciparum malaria has been reported in a 14year child. ${ }^{7}$

Bell's palsy is a facial nerve palsy involving the lower motor neuron. Bell's palsy results in weakness of facial muscles. ${ }^{8}$ Bell's palsy, i.e. lower motor neuron seventh nerve palsy has been reported following dengue infection. ${ }^{8}$, Campylobacter enteritis. ${ }^{9}$, Rickettsial infection. ${ }^{10}$, varicella zoster virus reactivation. ${ }^{11}$ However, our literature search did not reveal any report of bilateral Bell's palsy after malaria. Drooling of saliva from angles of mouth and inability to close eyes were the chief complaints which suggested the diagnosis of Bell's palsy in our case. The MRI of brain did not suggest any evidence of central nervous pathology that possibly might cause seventh nerve paralysis. To our knowledge, this is the first case report of bilateral lower motor neuron disease following P. vivax infection. P. vivax can result in relapse with varying clinical profile and drug response between patients. ${ }^{1}$ The patient had received treatment for malaria, but no radical treatment which might have caused relapse of P. vivax. Though we could not confirm, but strongly feel that the relapse of malaria was responsible for the symptoms of lower motor neuron palsy. The mechanisms of development of bilateral lower motor neuron palsy in this case are not known due to a paucity of literature due to rare occurrence. We feel systemic inflammatory response due to $\mathrm{P}$. vivax infection could be the possible cause of the disease in this patient. $^{3}$

\section{CONCLUSION}

To the best of our knowledge, this is the first case report of P. vivax malaria associated bilateral lower motor neuron palsy. In a tropical country like India due to endemic nature, malaria may be considered among the causes of Bell's palsy.

\section{REFERENCES}

1. Joshi H, Prajapati SK, Verma A, et al. Plasmodium vivax in India. Trends Parasitol 2008;24(5):228-35.

2. Aashish A, Manigandan G. Complicated vivax malaria, an often underestimated condition-case report. J Family Community Med 2015;22(3):180-2.

3. Lakhotia M, Pahadiva HP, Kumar H, et al. Acute pancreatitis, ascites, and acute renal failure in plasmodium vivax malaria infection, a rare complication. Trop Parasitol 2015;5(2):120-2.

4. Patel DN, Pradeep P, Surti MM, et al. Clinical manifestations of complicated malaria an overview. JIACM 2003;4(4):32331.

5. Sidhu J, Maheshwari A, Gupta R, et al. Acute disseminated encephalomyelitis after plasmodium vivax infection: case report and review of literature. Paediatr Rep 2015;7(2):5859. doi: 10.4081/pr.2015.5859.

6. Kasundra GM, Bhargava AN, Bhushan B, et al. Postplasmodium vivax malaria cerebellar ataxia and optic neuritis: a new form of delayed cerebellar ataxia or cerebellar variant of acute disseminated encephalomyelitis? J Paediatr Neurosci 2015;10(1):58-60.

7. Duque V, Seixas D, Ventura C, et al. Plasmodium falciparum malaria, bilateral sixth cranial nerve palsy and delayed cerebellar ataxia. Infect Dev Ctries 2012;6(3):290-4.

8. Peter S, Malhotra N, Peter P, et al. Isolated Bell's palsy - an unusual presentation of dengue infection. Asian Pac J Trop Med 2013;6(1):82-4.

9. Powell MR. Bell's palsy presenting after a case of campylobacter enteritis. Aviat Space Environ Med 2013;84(5):525-7.

10. Nilsson $K$, Wallmenius $K$, Hartwig $S$, et al. Bell's palsy and sudden deafness associated with Rickettsia spp. infection in Sweden. A retrospective and prospective serological survey including PCR findings. Eur J Neurol 2014;21(2):206-14.

11. Abdel-Aziz M, Azab NA, Khalifa B, et al. The association of varicella zoster virus reactivation with Bell's palsy in children. Int N Paediatr Otorhinolaryngol 2015;79(3):32831. 